\title{
Ecological succession of a natural community of Castanopsis sclerophylla on Laoshan Island, China
}

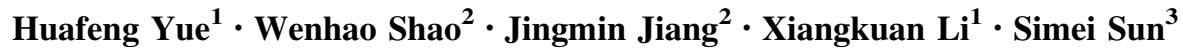

Received: 14 September 2014 / Accepted: 2 March 2015/Published online: 23 April 2016

(c) The Author(s) 2016. This article is published with open access at Springerlink.com

\begin{abstract}
Castanopsis sclerophylla was surveyed for its root turion capacity on Laoshan Island in Zhejiang Province and dispersion patterns of seedlings, genetic diversity and genetic variation coefficient was studied using a SSR (simple sequence repeat) molecular marker technique to explore the genetic diversity of C. sclerophylla (Lindl.) Schott as a community and evaluate the community's development. The results showed that $C$. sclerophylla had strong root turion capacity, of which type Re 2 was the most frequent, accounting for 32.4 and $82.4 \%$ of the seedlings under the stock plant were from within-community mating; the 6 pairs of SSR primers chosen yielded high resolution with $97.6 \%$ polymorphic sites; the within-community genetic diversity was over $88.9 \%$ with stock plants $(0.49)>$ seedling plants $(0.45)$. Apparently, C. scerophyllan on Laoshan Island, propagating
\end{abstract}

Project founding: This study was funded by the Key Project of Science and Technology Department of Zhejiang Province (2006C12059-3) and National Natural Science and Technology Resources Platform Project of China (2006DKA21003-09).

The online version is available at http://www.springerlink.com

Corresponding editor: Chai Ruihai

Jingmin Jiang

120695387@qq.com

1 Non-timber Forestry Research and Development Center, Chinese Academy of Forestry, and China Paulownia Research and Development Center, No. 3, Weiwu Road, Zhengzhou City 450003, People's Republic of China

2 Research Institute of Subtropical Forestry, Chinese Academy of Forestry, No. 73, Daqiao Road, Fuyang City 31140, People's Republic of China

3 Dazu County Forestry Bureau, No. 58, West Nanhuan Road, Chongqing City 402360, People's Republic of China mainly by root turions, has developed high genetic diversity within a short period, keeping the community in a stage of stable growth and moving toward a climax community. The tillers, however, aggravate closing of the community so that it receives less pollen from outside. Within-community mating is thus reaching seriously high levels, which can lead to lower within-community genetic variation, a decline in DNA genetic diversity, and is bad for its development. Therefore, human interference should be taken to expand genetic exchange among communities.

Keywords Castanopsis scerophylla $\cdot$ Ecological succession - Genetic diversity - Natural communities . SSR molecular marker

\section{Introduction}

Castanopsis sclerophylla (Lindl.) Schott. is a monoecious, and evergreen, broad-leaved canopy tree that is widely distributed in South and East Asia, and cultured in part of North America (Peter 2002; Shi et al. 2011). It can be used as a marker tree to distinguish between northern and southern climates (Huang et al. 2009). The wood and fruit are valuable, and glossy evergreen leaves and white flowers cover the tree, making it very desirable with potential to become a popular landscape and ornamental tree (Peter 2002; Tu et al. 2008). In recent years, with the increase of the tree's economic value, natural plants are constantly threatened. Further, because they grow slowly, natural trees are decreasing in number, its habitats are seriously fragmented, isolating natural populations, which will reduce its genetic variation (Wang et al. 2012). Under these circumstances, scholars are focusing research on relevant issues such as population biomass (Zhang and Song 2001), 
propagation mode (Peter 2002), population structure and succession (Tong et al. 2007a, b; Zhang et al. 2007), molecular marker primer design and large-scale comparisons of the genetic structures of different populations (Shi 2008, Shi et al. 2011).

Laoshan Island is a rare natural community of C. sclerophylla, which has survived because of its isolation and the enhanced awareness for protecting the environment and wild plants. As the dominant tree in the broadleaf-evergreen forest, the importance value of $C$. sclerophylla overs $60 \%$ on the island communities (Qin 2001). They are currently propagated by seeds and stem cuttings (Peter 2002); however, during the island survey, not many seedlings were found under the stock plants, piquing our interest. To explore the influence of the plant's breeding system on its genetic structure as well as the community's structural features and evaluate its future development, we analyzed the genetic diversity of two generations of $C$. sclerophylla (seedling plants and stock plants) using SSR molecular markers because of the good genome coverage (Ho et al. 2006; Feng et al. 2006; Goetze et al. 2015; Queiroz et al. 2015). We determined the genetic diversity levels of $C$. sclerophylla communities propagated by seeds and root turions, providing a theoretical foundation for the development and protection of this tree.

\section{Materials and methods}

\section{Study site}

Laoshan Island belongs to Chun'an County, Zhejiang Province between $29^{\circ} 11^{\prime}-30^{\circ} 02^{\prime} \mathrm{N}$ and $118^{\circ} 21^{\prime}-119^{\circ} 20^{\prime} \mathrm{E}$ (Fig. 1). It has an area of $8749,000 \mathrm{~m}^{2}$, altitude approximately from 108 to $408.5 \mathrm{~m}$ above sea level, a central Asian tropical monsoon climate, with mean annual temperature of $17{ }^{\circ} \mathrm{C}$, accumulated temperature $\left(\geq 10^{\circ} \mathrm{C}\right)$ of $5410{ }^{\circ} \mathrm{C}$, mean annual frost-free period of 263 days, the mean annual rainfall of $1430 \mathrm{~mm}$, mean annual days of rainfall of 155 days, mean annual relative humidity is $76 \%$, mean annual sunshine hours of $1951 \mathrm{~h}$, total annual radiation of $4475 \mathrm{MJ} \mathrm{m}^{-2}$, and annual evaporation of $1381.5 \mathrm{~mm}$. Soil type is red loam or lithology, nutrient content is low. The crown density index of forest is between 0.7 and 0.9. Associated plants in the tree layer are mainly Pinus massoniana Lamb, Lithocarpus glaber, $C y$ clobalanopsis glauca (Thunberg) Oersted, Quercus glandulifera var. brevipetiolata Nakai, and Vaccinium carlesii Dunn, Syzygium buxifolium Hook. and Arn., Eurya muricata Dunn in the shrub layer. The main herbaceous plant is Dicranopteris dichotoma (Thunb.) Bernh. Among the interlayer are Smilax glabra Roxb. and Wisteria sinensis (Sims) Sweet (Zhang et al. 2007; Xiong et al. 2010).

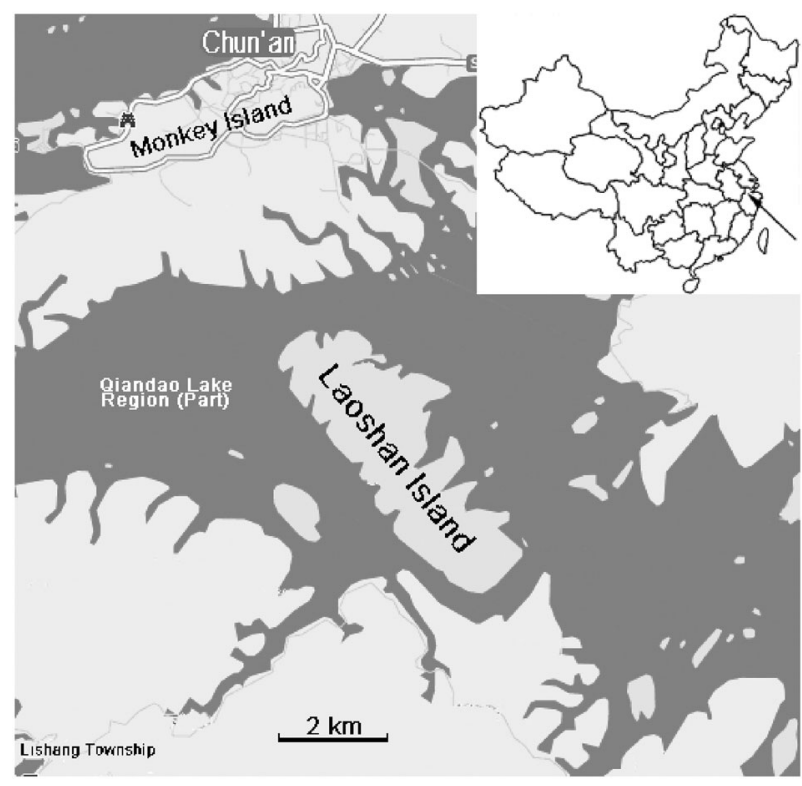

Fig. 1 Location of study area in China

\section{Sampling methods}

A permanent plot of $400 \mathrm{~m}^{2}$ was established and divided into 16 small blocks $(5 \times 5 \mathrm{~m})$. Since $C$. sclerophylla has a strong root turion capacity, we took the root turion of each plant as the statistical unit when recording the diameter at breast height (DBH) and height of the root turions. DHB, girth, coverage and height of plants of all stock and their root turions were measured, and the tillers and seedlings were counted. Complete leaves for all root turions were collected, sealed in valve bags with silica gel as the drying agent, and then used for SSR genetic analysis.

There were 34 stock plants and 89 root turions, which were all adult plants. We collected leaves for DNA extraction from the 34 stock plants and 19 seedlings (heights of $0.2-2.0 \mathrm{~m}$ ) found under the trees.

\section{SSR-PCR method}

Total genomic DNA from leaf samples of the stock plants and the root turions were extracted using a Plant Genomic DNA Pillar Extraction Kit (Tianenze, Beijing, China). DNA concentration and quality were determined using an ultramicro ultraviolet spectrophotometer (Nandrop 2000/200C, Thermo, American). Six pairs of primers (Table 1) were selected from 13 pairs of primers for Castanopsis cuspidate (Ueno et al. 2000, 2003). The PCR reaction volume was $25 \mu \mathrm{L}$ and contained $2 \mu \mathrm{L} 10 \times$ Buffer, $2 \mu \mathrm{L} 1.5 \mathrm{mmol} \mathrm{L}^{-1}$ $\mathrm{MgCl}_{2}, 2 \mu \mathrm{L} 0.2 \mathrm{mmol} \mathrm{L}^{-1}$ of each dNTP, $1 \mu \mathrm{L}$ each of Primer $\mathrm{F}$ and Primer R, $0.5 \mu \mathrm{L}$ Taq DNA polymerase (1 $\mathrm{U}_{\mu} \mathrm{L}^{-1}$, TaKaRa, Shenyang, China), $15.5 \mu \mathrm{L} \mathrm{H}_{2} \mathrm{O}$, and $1 \mu \mathrm{L}$ DNA template (approximately $50 \mathrm{ng} \mathrm{LL}^{-1}$ ). The 
Table 1 Sequences of SSR primers used in the present study

\begin{tabular}{|c|c|c|}
\hline Primer & Sequence $\left(5^{\prime}-3^{\prime}\right)$ & $\mathrm{T}\left({ }^{\circ} \mathrm{C}\right)$ \\
\hline \multirow[t]{2}{*}{ *Cuc16H15 } & F: CTGCCTATCССССТСТАСТTT & \multirow[t]{2}{*}{63.5} \\
\hline & R: AAGCCCGTACAATTATATGAATGA & \\
\hline \multirow[t]{2}{*}{ *Ccu33H 25} & F: GGGTTTGGGTGGAGAAGTC & \multirow[t]{2}{*}{66.5} \\
\hline & R: GATCGGTACAACCCCTCACT & \\
\hline \multirow[t]{2}{*}{${ }^{\dagger} \mathrm{Ccu} 62 \mathrm{~F} 15$} & F: TTGCATCCTCAGCTTTCTCA & \multirow[t]{2}{*}{64.5} \\
\hline & R: GCССТСТССТААСАССААТААТАС & \\
\hline \multirow[t]{2}{*}{${ }^{\dagger} \mathrm{Ccu} 87 \mathrm{~F} 23$} & F: CGGAACCTAACACCACTACC & \multirow[t]{2}{*}{60} \\
\hline & R: CTCCCTCCCTATCATACTTTGA & \\
\hline \multirow[t]{2}{*}{${ }^{\dagger} \mathrm{Ccu} 93 \mathrm{H} 17$} & F: GGCAACATCAAGGTATTTC & \multirow[t]{2}{*}{53} \\
\hline & R: CTAAGCAATTTATATTGTCCAAA & \\
\hline \multirow[t]{2}{*}{${ }^{\dagger} \mathrm{Ccu} 97 \mathrm{H} 18$} & F: GATCATAGCTAAAATAGTAACT & \multirow[t]{2}{*}{55} \\
\hline & R: CGAGGACATAGATAGAGA & \\
\hline
\end{tabular}

* Primers are from Ueno et al. (2000)

$\dagger$ Primers are from Ueno et al. (2003)

program for the PCR amplification included an initial denaturation of $94^{\circ} \mathrm{C}$ for $3 \mathrm{~min}$; followed by 34 cycles of $94{ }^{\circ} \mathrm{C}$ for $30 \mathrm{~s}, 64{ }^{\circ} \mathrm{C}$ for $40 \mathrm{~s}$, and $72{ }^{\circ} \mathrm{C}$ for $30 \mathrm{~s}$; then a final extension at $72{ }^{\circ} \mathrm{C}$ for $7 \mathrm{~min}$. Amplified products were electrophoresed on $8 \%$ denaturing polyacrylamide gels (DYY-12, Liuyi, Beijing, China). Fluorochrome GelRed was added (Liu et al. 2011), and the gels were visualized with a Gel Imaging System (Gel Doc 2000, Bio-Rad, California, USA).

\section{Data analysis}

Genetic elimination and likelihood analyses were adopted to analyze the parents of $C$. sclerophylla seedlings ( $\mathrm{Wu}$ et al. 2008; Fritsch and Rieseberg 1992). Genetic diversity and differentiation were analyzed using POPGENE 1.32 software (Yeh et al. 1999), the index including the mean number of alleles $\left(N_{\mathrm{a}}\right)$, percentage of polymorphic loci $\left(P_{\mathrm{p}}\right)$, observed heterozygosity $\left(H_{\mathrm{o}}\right)$, expected heterozygosity $\left(H_{\mathrm{e}}\right)$, inbreeding coefficient $\left(\mathrm{F}_{\mathrm{IS}}\right)$, coefficient gene differentiation $\left(G_{\mathrm{ST}}\right)$, estimate of gene flow from GST $(\mathrm{Nm})$, gene diversity within communities $\left(H_{\mathrm{S}}\right)$, total gene diversity $\left(H_{\mathrm{T}}\right)$, and gene diversity between communities $\left(D_{\mathrm{ST}}\right)$. The mating pattern was assessed according to the method of Kikuchi et al. (2009).

\section{Results}

\section{Root turion capacity of Castanopsis sclerophylla}

C. sclerophylla has strong root turion capacity; 1-5 different tiller types were found around every stock plant in the survey (Fig. 2). In the surveyed forest, only 19 seedling plants but 102 root turions, with DBH of $15-30 \mathrm{~cm}$, were found. Of the 102 root turions, type Re5 (five root turions within one tree) was the least frequent $(5.9 \%$ of total turions) and type $\operatorname{Re} 2$ (two root turions within one tree) was the most frequent $(32.4 \%), \operatorname{Re} 3$ (three root turions within one tree) accounted for $26.5 \%, \operatorname{Re} 1$ (one root turion within one tree) and Re4 (four root turions within one tree) each accounted for $17.6 \%$.

\section{Dispersal pattern of seedling plants}

The rate of inbreeding is high among communities because of the mode of seed dispersal. When the distance between the parents and the seedlings was analyzed with a likelihood analysis, $65.8 \%$ of the seeds were dispersed 5-10 m from the parent plant, the next most frequent distance was 10-15 $\mathrm{m}$, and the fewest were dispersed $0-5 \mathrm{~m}$ (data not shown). This dispersal pattern was due to gravity and the influence of crown shading on germination and plant growth. In the whole community, 4 of the 6 pairs of SSR primers detected genetic polymorphism; thus, only 3 parents can be confirmed through genetic elimination, assuming the genotype of each gene locus was aa, bb, cc and dd. To evaluate the influences of other ecological factors on the observed mating patterns, we regressed the relative pollination success of each pollen parent. The results showed that although the quantity of root turions was large, 12 genotypes were found among 19 seedling plants, and 3 of them resulted from external pollen hybridization, accounting for $15.8 \%$ of the total (Table 2). Furthermore, the parents of 9 genotypes were found in the minority $(7,8,9,12,13,15,21,23,24,25,26)$, showing that the rate of inbreeding is high.

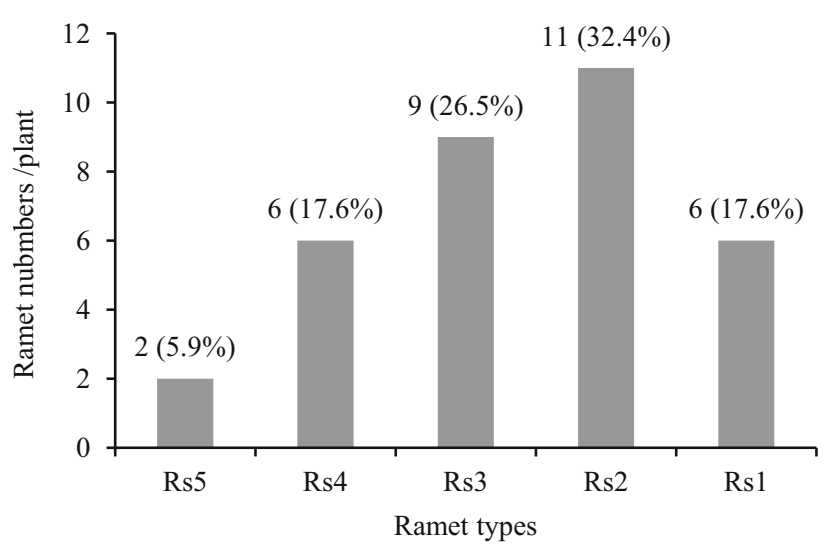

Fig. 2 Rate of ramet types of stock plants. Rs 5 five root turions within one tree, $R s 4$ four root turions within one tree, $R s 3$ three root turions within one tree, $R s 2$ two root turions within one tree, $R s 1$ one root turion within one tree 
Table 2 Mating patterns of seedling community of Castonopsis sclerophylla

\begin{tabular}{lll}
\hline Samples & Genome types & Mating patterns \\
\hline 35 & bbcd/bdcd & $(9,12,13,15,21,23,24,25,26) \times(9,12,13,15,21,23,24,25,26)$ \\
36 & bbcd/bdcd & Same as sample 35 \\
37 & bbcd/bdcd & Same as sample 35 \\
38 & bbcd/bdcd & Same as sample 35 \\
39 & bdcd/ddcb & $(8,9) \times$ outer pollen \\
40 & aabd/bbcd & $12 \times(12,14,15)$ \\
41 & abcd/bbcd & $(7,8,9) \times 5$ \\
42 & abcd/bbcd & Same as sample 41 \\
43 & abcd/bbcd & Same as sample 41 \\
44 & ddcb/ddcb & $15 \times 4$ \\
45 & abdb/bdcd & $(2,4,6) \times(7,9,10,11)$ \\
46 & bbcd/bdcd & Same as sample 35 \\
47 & bbcd/bdcd & Same as sample 35 \\
48 & bcbd/dbdb & $17 \times$ outer pollen \\
49 & abcd/bbcd & $3 \times(12,13)$ \\
50 & bbcd/bccd & $6 \times(5,4)$ \\
51 & aabd/bcbd & $8 \times(13,14)$ \\
52 & bcdd/adbd & $33 \times(31,32,30)$ \\
53 & abbc/bcad & $33 \times$ outer pollen \\
54 & abcd/bbcd & Same as sample 41 \\
\hline
\end{tabular}

\section{Genetic diversity of different generations of Castanopsis sclerophylla}

For high resolution differentiation, the six pairs of SSR primers selected could be easily distinguished and were suitable for this research (Fig. 3). From the analysis of the stock plant community, the index $N_{\mathrm{a}}$ was $3.68, P_{\mathrm{p}}$ was $100 \%, H_{o}$ was 0.49 , and $H_{\mathrm{e}}$ was 0.23 ; in the seedling plant community, $N_{\mathrm{a}}$ was $2.83, P_{\mathrm{p}}$ was $97.6 \%, H_{o}$ was 0.42 , and $H_{\mathrm{e}}$ was 0.20 (Table 3 ). The $F_{\text {IS }}$ of both the stock and seedling plants was over 0 , indicating that the C. scerophyllan community has low heterozygosity and different levels of inbreeding.

\section{Genetic variation of different generations of Castanopsis sclerophylla}

Genetic diversity of the stock plants was higher than in the seedlings on Laoshan Island. For the stock plants, total $H_{\mathrm{T}}$ was 0.49 (Table 4 ), of which within-community $H_{\mathrm{S}}$ and among-community $D_{\mathrm{ST}}$ was 0.45 and 0.04 , respectively, showing that $91.8 \%$ of the genetic diversity of the stock plants resulted from within-population variation; for the seedling plants, the total $H_{\mathrm{T}}$ was 0.45 , of which withincommunity $H_{\mathrm{S}}$ and among-community $D_{\mathrm{ST}}$ was 0.40 and 0.05 respectively, showing that $88.9 \%$ of their genetic diversity was from within-community variation. The $G_{\mathrm{ST}}$ of the stock plants and seedling plants was 0.08 and 0.11 , respectively; thus, they both had a moderate degree of variation. Gene flow strongly affected the genetic structure of the population; $\mathrm{Nm}$ of the stock and seedling plants were both above 1, proving that the two generations of $C$. sclerophylla both had a high frequency of gene exchange and thus low genetic variation.

\section{Discussion}

Root turion propagation is an adaptive measure of the natural community of $C$. sclerophylla on Laoshan Island. After 40 years of natural regeneration and secondary succession, $C$. sclerophylla has become one of the most dominant tree species of the area. Similar to other plants of Fagaceae, C. sclerophylla has shown relatively high adaptability in the area, which causes canopy closure and greatly reducing light under the trees, leading to poor seed germination and seedling growth. Furthermore, the nutritious seeds of $C$. sclerophylla seeds are the main food source of rodents, so few seedlings are produced. The root turions are nutritionally well supplied by the stock plant; therefore, root turions have become and will continue to be the main mode of propagation for C. sclerophylla, as it has for the natural regeneration of many species (Yu et al. 2009; Takahashi et al. 2010; Farahat and Lechowicz 2013).

Root turion regeneration acts against future development of the species. There are many stock plants on Laoshan Island, and each has 2.6 root turions on average. In the analysis on the genetic dispersion pattern of the 
Fig. 3 Pattern of bands amplified from DNA extracted from Castonopsis sclerophylla leafusing PCR and primer pair Cuc16H15 and Ccu87F23. Lane $M=250$ bp DNA ladder, lanes $1-27=$ amplification products for 27 samples by the SSR primers Cuc16H15 and Ccu87F23

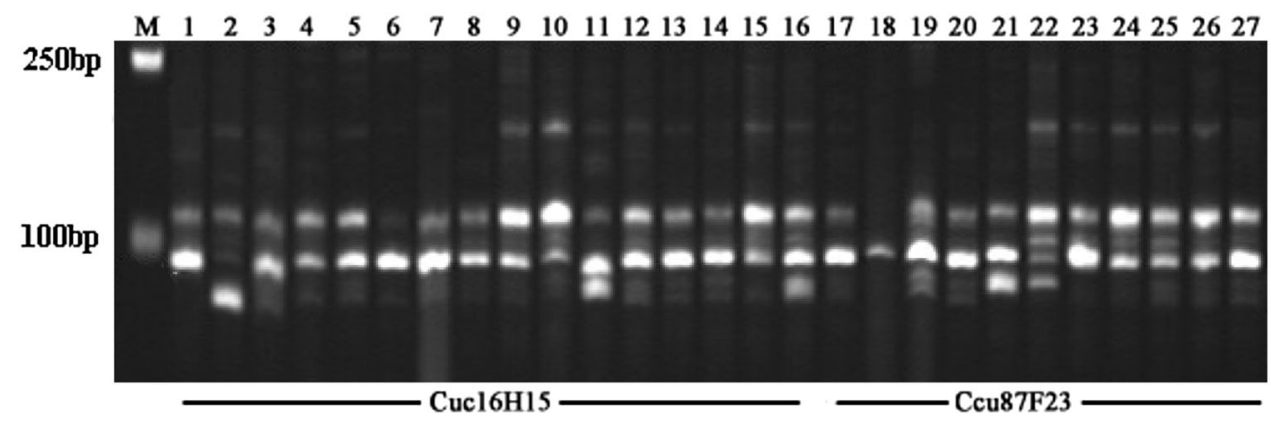

Table 3 Genetic diversity of stock plants and seedling communities of Castonopsis sclerophylla

\begin{tabular}{lllllll}
\hline Community & Size & $N_{\mathrm{a}}$ & $P_{\mathrm{p}}(\%)$ & $H_{\mathrm{e}}$ & $H_{\mathrm{o}}$ & $F_{\text {IS }}$ \\
\hline Seedlings & 19 & 2.83 & 97.6 & 0.42 & 0.20 & 0.52 \\
Stock plants & 34 & 3.68 & 100 & 0.49 & 0.23 & 0.53 \\
\hline
\end{tabular}

$N_{\mathrm{a}}$ mean number of alleles; $P_{\mathrm{p}}$ percentage of polymorphic loci; $H_{\mathrm{e}}$ expected heterozygosity; $H_{\mathrm{o}}$ observed heterozygosity; $F_{\mathrm{IS}}$ inbreeding coefficient

Table 4 Coefficient of genetic differentiation between seedlings and stock plants of Castonopsis sclerophylla

\begin{tabular}{llllll}
\hline Community & $H_{\mathrm{T}}$ & $H_{\mathrm{S}}$ & $D_{\mathrm{ST}}$ & $G_{\mathrm{ST}}$ & $N m$ \\
\hline Seedlings & 0.45 & 0.40 & 0.05 & 0.11 & 2.02 \\
Stock plants & 0.49 & 0.45 & 0.04 & 0.08 & 2.88
\end{tabular}

$H_{\mathrm{T}}$ total gene diversity; $H_{\mathrm{S}}$ gene diversity within communities; $D_{\mathrm{ST}}$ gene diversity between communities; $G_{\mathrm{ST}}$ coefficient gene differentiation; $\mathrm{Nm}$ estimate of gene flow from GST

seedling plants in the plot, $84.2 \%$ of the seedling plants resulted from within-community mating. This large quantity of root turions has hindered pollination by pollen from outside the community and increased the rate of withincommunity pollination, hence, only genotypes within the community have contributed to the genotypes in the filial generation, increasing within-community inbreeding. This inbreeding is another reason that genetic diversity is higher in the stock plants than in the seedlings. This conclusion differs from that of Shi (2008), who argued that the withincommunity inbreeding of $C$. sclerophylla on Laoshan Island was due to the wind direction, which affected the receipt of pollen from marginal communities. High genetic diversity has been an adaptive measure of a population to cope with bad environmental conditions (Ohsawa and Ide 2008). On Laoshan Island, both stock and seedling plants of $C$. sclerophylla have genetic diversity of over $88.9 \%$, making $81 \%$ of its genetic variation from within the population (Shi 2008).

Population fragmentation significantly reduces population genetic structure, but as a whole, gene flow does not change (Wang et al. 2011, 2012). For C. sclerophylla, pollen spread has become more efficient although seed transmission has been restricted concomitant with the fragmentation, which has compensated for the disadvantage from restricted seed transmission. The research of Shi (2008) and Wang $(2012,2011)$, however, encompassed the genetic structure of $C$. sclerophylla on the larger scale of the whole Qiandao Lake region. On Laoshan Island, however, we believe the frequent genetic exchange within the community has prevented genetic drift, which has brought about low genetic variation within a short period, but the long-term inbreeding will increase the risk of within-community genetic drift and retrogression of the genetic structure. The result of the lower genetic diversity of this natural community of C. sclerophylla, however, differs from the case for Pinus koraiensis, which declined in its natural distribution due to anthropogenic and environmental factors not to low genetic diversity (Feng et al. 2006).

The current level of forest destruction observed in this area is still not affecting the degree of gene flow and levels of genetic diversity; the natural root turion regeneration of C. sclerophylla is an adaptation to the severe environment on Laoshan Island and will maintain high genetic diversity within the community, at least for a certain period. Therefore, as long as no great disturbance (e.g., wind throw, fire, water logging or pest and disease) alters the environment, the community will continue its gradual succession to a climax community; however, the overall genetic diversity of the community will decline, which is bad for sustainable development of the species. To solve this problem, human interference should be taken to expand gene flow from other communities and increase the genetic diversity index of this community. On the basis of our findings, we believe that the creation of a protected natural area in the region where the species occurs would be the best conservation strategy for C. sclerophylla.

Acknowledgements This study was funded by the Key Project of Science and Technology Department of Zhejiang Province (2006C12059-3) and National Natural Science and Technology Resources Platform Project of China (2006DKA21003-09). 


\section{Compliance with ethical standards}

Conflict of Interest The authors declare that they have no conflict of interest.

Open Access This article is distributed under the terms of the Creative Commons Attribution 4.0 International License (http://crea tivecommons.org/licenses/by/4.0/), which permits unrestricted use, distribution, and reproduction in any medium, provided you give appropriate credit to the original author(s) and the source, provide a link to the Creative Commons license, and indicate if changes were made.

\section{References}

Farahat E, Lechowicz MJ (2013) Functional ecology of growth in seedlings versus root sprouts of Fagus grandifolia Ehrh. Trees 27(1):337-340

Feng FJ, Han SJ, Wang HM (2006) Genetic diversity and genetic differentiation of natural Pinus koraiensis population. J For Res 17(1):21-24

Fritsch P, Rieseberg LH (1992) High outcrossing rates maintain male and hermaphrodite individuals in population of the flowering plant Datisca glomerata. Nature 359:633-636

Goetze M, Büttow MV, Zanella CM, Paggi GM, Bruxel M, Pinheiro FG, Sampaio JAT, Palma-Silva C, Cidade FW, Bered F (2015) Genetic variation in Aechmea winkleri, a bromeliad from an inland Atlantic rainforest fragment in Southern Brazil. Biochem Syst Ecol 58:204-210

Ho WS, Wickneswari R, Mahani MC, Shukor MN (2006) Comparative genetic diversity studies of Shorfa curtisii (Dipterocarpaceae): an assessment using SSR and DAMD markers. J Trop For Sci 18(1):22-35

Huang HS, Lin GW, Sha CP (2009) The future development and afforestation technology in Castanopsis sclerophylla. J Changchun Univ Sci Technol (Higher Education Edition) 4(6):185-186 (in Chinese)

Kikuchi S, Shibata M, Tanaka H, Yoshimaru H, Niiyama K (2009) Analysis of the disassortative mating patter in a heterodichogamous plant, Acer mono Maxim: using microsatellite markers. Plant Ecol 204(1):43-54

Liu MP, Fu DL, Tian M, Fu JM (2011) A new bands display technology of microsatellite DNA. Afr J Biotechnol 10(83): 19276-19279

Ohsawa T, Ide Y (2008) Global patterns of genetic variation in plant species along vertical and horizontal gradients on mountains. Global Ecol Biogeogr 17:152-163

Peter JC (2002) Propagation of Castanopsis scerophylla and Lindera umbellata by stem cutting and nitrogen nutrition of containerized ternstroemia gymnanthera. Dissertation for Master's degree of North Carolina State University, Carolina

Qin GE (2001) Study on hydro-ecological benefits of everygreen broadleaved forest at the Qiandao Lake Region. For Res 14:595-602 (in Chinese)

Queiroz A, Assunção A, Ramadas I, Viegas W, Veloso MM (2015) Molecular characterization of portuguese pear landraces (Pyrus communis L.) using SSR markers. Sci Hortic-Amst 183:72-76
Shi MM (2008) Acomparative study of genetic structure between the central and peripheral populations of Castanopsis sclerophylla. Dissertation for Master's degree of East China Normal University, Shanghai City (in Chinese)

Shi YS, Zhang J, Jiang K, Cui MY, Li YY (2011) Development and characterization of polymorphic microsatellite markers in Castanopsis scerophylla (Fagaceae). Am J Bot 98:e19-e21

Takahashi K, Arii K, Lechowicz MJ (2010) Codominance of Acer saccharum and Fagus grandifolia: the role of Fagus root sprouts along a slope gradient in an old-growth forest. J Plant Res 123(5):665-674

Tong LL, Xu XG, Guan QW, Tang GG (2007a) Community structure analysis of Castanopsis sclerophylla forest in mount Niushou forest park of Nanjing city. J Northeast For Univ 35(3):23-26 (in Chinese)

Tong LL, Xu XG, Guan QW, Tang GG (2007b) Community structure analysis of Castanopsis sclerophylla forestry in mount Niushou Forest Park of Nanjing city. J Northeast For Univ 35(3):23-26 (in Chinese)

Tu ZC, Liu GX, Dou YX, Liu CM, Lin DR (2008) Study on extraction and purification total flavones from the fruits of Castanopsis sclerophylla. Food Res Dev 29(1):33-36 (in Chinese)

Ueno S, Yoshimaru H, Kawahara T, Yamamoto S (2000) Isolation of microsatellite markers in Castanopsis cuspidata var. sieboldii Nakai from an enriched library. Mol ecol 8(244):335-336

Ueno S, Yoshimaru H, Kawahara T, Yamamoto S (2003) A further six microsatellite markers for Castanopsis cuspidata var. sieboldii Nakai. Conserv Genet 4(6):813-815

Wang R, Compton SG, Chen XY (2011) Fragmentation can increase spatial genetic structure without decreasing pollen-mediated gene flow in a wind-pollinated tree. Mol Ecol 20(21):4421-4432

Wang R, Compton SG, Shi YS, Chen XY (2012) Fragmentation reduces regional-scale spatial genetic structure in a windpollinated tree because genetic barriers are removed. Ecol Evol 2(9):2250-2261

Wu JC, Peng XM, Zheng YX, Zhang YP (2008) Outcrossing rate and gene flow estimation of Azadirachta indica. For Res 21(5):593-598

Xiong N, Jin ZX, Gu JJ, Wang XW, Song WJ (2010) Population structure and distribution pattern of dominant tree species in a secondary forest on Laoshan island of Qiandao Lake Region. Chin J Ecol 29(5):847-854 (in Chinese)

Yeh F, Yang R, Boyle T (1999) POPGENE, Version 1.32. Mircosoft window based freeware for population genetic analysis. Edmonton: Centre for international Forestry Research, University of Alberta

Yu S, Wang R, Liu M, Yang SZ, Luo Y, Chen XY (2009) Species composition and sprouting regeneration of Fagus engleriana community in Tianmushan Mountain. Chin J Ecol 28(2):182-187 (in Chinese)

Zhang GF, Song YC (2001) Studies on the biomass of Castanopsis sclerophylla + Quercus fabri shrubland in Tiaotong region, Zhejiang province. J Wuhan Bot Res 19(2):101-106 (in Chinese)

Zhang X, Xu G, Shen DW, Gu Y, Gao H, Luo XH, Chen XY (2007) Maintenance and natural regenetation of Castanopsis sclerophylla populations on islands of Qiandao Lake Region. Acta Ecol Sin 27(2):424-431 (in Chinese) 